\title{
Temperature dependency of whole blood viscosity and red cell properties in desert ungulates: Studies on scimitar-horned oryx and dromedary camel
}

\author{
Ursula Windberger ${ }^{\mathrm{a}, *}$, Roland Auer ${ }^{\mathrm{a}}$, Roberto Plasenzotti ${ }^{\mathrm{a}}$, Stephanie Eloff ${ }^{\mathrm{b}}$ and \\ Julian A. Skidmore \\ ${ }^{\mathrm{a}}$ Center for Biomedical Research, Medical University Vienna, Austria \\ $\mathrm{b}_{\text {University of Pretoria Biomedical Research Centre, South Africa }}$ \\ ${ }^{\mathrm{c}}$ Camel Reproduction Center, Dubai, United Arab Emirates

\begin{abstract}
${ }^{*}$ Corresponding author: Ursula Windberger, Decentralized Biomedical Facilities, Center for Biomedical Research, Borschkegasse 8a, 1090 Vienna, Austria. E-mail: ursula.windberger@meduniwien.ac.at.
\end{abstract}

\begin{abstract}
BACKGROUND: The dromedary camel and the oryx antelope are exposed to excessive heat and solar radiation in their desert habitat. Desertification of areas with by now little rainfall may occur eventually. Well-adapted large animal species show us what is needed to survive in scorching regions.

METHODS: Four scimitar-horned oryx antelopes (Oryx dammah), 10 camels (Camelus dromedarius), nine South African Merino sheep, and 17 Nguni cows were tested for RBC aggregation, RBC elongation, and plasma viscosity. The temperature dependency of blood viscosity was tested in 10 camels and compared to human reference values.

RESULTS: Unlike sheep, Nguni cow, and dromedary camel, oryx RBCs aggregate in native plasma (M0:5.2 (3.3/6.7); M1:18.1 (16.7/27.9); Myrenne MA1). Elongation indices of oryx RBCs were intermediate to low (EImax: 22.6 (19.2/25.3); SS1/2 3.67 (2.52/4.95); Rheodyn SSD). Camel RBCs did not display the typical SS/EI curve by rotational ektacytometry. In-vitro blood viscosity (Physica MCR302) was lower in camels than in human blood at equal hematocrit. A decrease of temperature had only little effect on camel blood. At $10 \mathrm{~s}^{-1}$, blood viscosity in camel increased from $2.18 \mathrm{mPa} * \mathrm{~s}(2.01 / 2.37)$ at $42^{\circ} \mathrm{C}$ to $4.39 \mathrm{mPa}^{*} \mathrm{~s}(4.22 / 4.51)$ at $12^{\circ} \mathrm{C}$. In human blood, viscosity ranged from $8.21 \mathrm{mPa}^{*} \mathrm{~s}(6.95 / 8.25)$ at $37^{\circ} \mathrm{C}$ to $15.52 \mathrm{mPa} * \mathrm{~s}$ $(14.25 / 16.03)$ at $12^{\circ} \mathrm{C}$. At $1000 \mathrm{~s}^{-1}$, blood viscosity in camel ranged from $2.00 \mathrm{mPa}^{*} \mathrm{~s}(1.95 / 2.04)$ at $42^{\circ} \mathrm{C}$ to $3.98 \mathrm{mPa}^{*} \mathrm{~s}$ $(3.88 / 4.08)$ at $12^{\circ} \mathrm{C}$. In human blood, viscosity ranged from $5.35 \mathrm{mPa}^{*} \mathrm{~s}(4.96 / 5.87)$ at $37^{\circ} \mathrm{C}$ to $11.24 \mathrm{mPa}{ }^{*} \mathrm{~s}(10.06 / 11.17)$ at $12^{\circ} \mathrm{C}$

CONCLUSIONS: Desert ungulates may need RBC membranes, which are fortified to withstand changes in osmolality during dehydration-rehydration cycles. This reduces RBC deformability. Dromedary camel blood does not undergo stark changes in viscosity with changes in temperature. Therefore, blood fluidity could be rather maintained during the day and night cycle. This should reduce the need of the vascularity to rhythmically adapt to changing shear forces when camels experience heterothermy.
\end{abstract}

Keywords: Oryx antelope, dromedary camel, red blood cells, deformability, aggregability, blood viscosity, temperature

\section{Introduction}

The dromedary camel and the oryx antelope are remarkable species, exposed to excessive heat and solar radiation during the day and relatively cold nights in their desert habitat. Desertification of areas with by now little rainfall may occur eventually. Well-adapted large animal species show us 
what is needed to survive in scorching regions. Mechanisms to tolerate high heat loads associated with dehydration were summarized recently for the dromedary camel [1] and for desert ungulates [2]. These mechanisms include low water turnover rates, fluid shift between compartments to maintain plasma volume [3], reduced urine and saliva production, urine and saliva concentration, reduction of the metabolic rate [4], selective brain cooling, and heterothermy [5, 6]. In a proteomics study, Warda et al. [7] found that heat shock proteins in brain and heart are overexpressed in the camel. The camel also expresses high levels of vimentin in hump adipocytes, affecting not only the lipid and glucose metabolism of the hump, but also underlining the importance to conserve cell shape and morphology. For the oryx antelopes, selective brain cooling and heterothermy was described [8,9], and there is evidence that heterothermy might have been induced by experimental dehydration [10].

Blood fluidity plays an important role in the context of heat exposure as viscosity is temperature dependent. If the blood temperature in directly irradiated superficial body regions increases, the blood viscosity will automatically decrease. When an animal experiences heterothermy, blood viscosity will increase during the night and decrease during the day with the periodic changes of the core temperature. The only exception from this notion would be if blood adapts its composition (e.g. its hematocrit) to the diurnal temperature variations to maintain a certain viscosity value throughout the nychthemeral temperature amplitude. This would actually make sense, since a certain level of blood viscosity is needed to maintain a functional capillary density [11-13]. By taking the shear stress stimulus into account, a lower blood viscosity during daytime would reduce the number of perfused capillaries, and heat convection by the flowing blood might be diminished. In-vitro experiments showed that shear thinning is affected by temperature in a logarithmic manner in human blood [14]. The higher the temperature, the lower is the shear thinning ability of blood. The adjustment of the viscosity value to the flow rate in a given vascular geometry helps to maintain a physiological capillary pressure $[15,16]$. If shear thinning is reduced in heterothermic animals in the afternoon, other mechanisms must come into effect to keep the capillary pressure low, and any increase of blood flow - e.g. as a result of exercise - should be avoided. Thus, timing of activity is essential under this circumstance, and it is reasonable to perform races in winter months during the early hours of a day.

Although vessel length, blood volumes and heart rate scales with the size of the species, the vascular geometry is in principle similar among all mammals. This is why animal models provide valuable insight in rheological studies. Whole blood viscosity (WBV) at high shear rates is quite similar between mammals, but WBV at low shear rate varies remarkably, for instance by a factor 8 between horse and camel at equal hematocrit levels [17, 18, own unpublished results]. Blood fluidity is also influenced by the RBC dynamics during flow [19], while the effect of shear strain on the RBC membrane motion depends on the membrane fluidity. RBC membrane viscoelasticity is a complex function of the lipid and protein composition of the bilayer and the protein assembly of the underlying spectrin network. Oryx antelopes have been studied for their RBC membrane composition by SDSPAGE [20]. Scimitar-horned oryx showed an unexpected high concentration of ankyrin. This may be the reason that ATP depleted RBCs were less prone to echinocytosis than human depleted RBCs. Camelid RBC has been studied in more detail. The fatty acids consist of shorter and more unsaturated chains [21]. The protein content is threefold compared to human. Band 3 protein has a higher molecular weight and thus a lower diffusivity in SDS-PAGE, and the cytoplasmic domain of band 3 protein shows limited rotation and a tight connection to ankyrin [20, 22-25]. This will contribute to the increased elastic shear modulus and Young's modulus of camelid red cells [26, own unpublished results]. Membrane proteins also determine the RBC surface charge through the glycosylation pattern. The camel RBC surface possesses a high amount of sialic acid moieties [27] resulting in a high surface charge. The electrochemical surface properties are the basis of the electrostatic double layer around RBCs, and the coherence between RBCs and plasma molecules determine the flow behavior of blood. 
Temperature not only lowers blood viscosity, but also modifies the mechanical properties of RBC membranes $[28,29]$. Our own results by using single cell force spectroscopy on camel RBCs show that apparent Young's modulus as well as adhesion force are affected by temperature (unpublished results). It might be possible that blood viscosity shows a different dependence on temperature among animal species, and in particular in species living in very cold or very hot environments. Such an effect was described for bowhead whales and Antarctic birds [30, 31]. Camels can modify their nychthemeral amplitude of body temperature by $6^{\circ} \mathrm{C}$ to prevent evaporative cooling and water loss [4]. They are also able to lower the brain temperature below the arterial blood temperature. Selective brain cooling (SBC) was also observed in oryx and in goat [9], although a previous study indicates that the degree of SBC might be too small to be relevant in free-ranging animals [32].

In the present study we investigated the deformability and aggregability of red cells of scimitarhorned oryx antelopes and the RBC aggregability of dromedary camels, and we compared the findings to cow and sheep, as well as to human reference values. We also measured the viscosity of camel and oryx blood plasma. With the obtained plasma viscosity values - and by knowing the MCHC of the RBCs in the blood samples used - it is possible to calculate the viscosity ratio between the dispersed and the continuous phases of the blood suspension. These values can be helpful to simulate the behavior of RBCs in shear flow [33]. For instance, the frequency of tank treading and the time constant for red cell shape recovery depends not only on the shear rate and the membrane fluidity, but also on this ratio [34-36]. In the dromedary camel we investigated the temperature dependence of the apparent viscosity of the native whole blood sample, and we compare the results to human reference values. We show that in-vitro blood viscosity is virtually maintained at steady levels in the camel during changes of temperature.

\section{Material and methods}

Four female scimitar-horned oryx antelopes (Oryx dammah) of the National Zoological Gardens (NZG), Pretoria, South Africa (housed at an altitude of $1300 \mathrm{~m}$ above sea level), and 10 female camels (Camelus dromedarius) of the Camel Reproduction Center Dubai, UAE (CRC; housed at sea level) were used. Nine Merino sheep and 17 Nguni cows housed at the University of Pretoria - Faculty of

Veterinary Sciences campus in Onderstepoort, South Africa were included into the study as well for the comparison of the RBC deformability and aggregability with oryx. Experiments were performed in January 2008 (oryx, sheep, cattle), and January 2017 (camel), resp. The veterinarians of the respective facilities declared all animals clinically healthy. Blood was withdrawn during a routine health check from the jugulary vein by a Vacuette ${ }^{\circledR}$ blood collection system $(21 \mathrm{G}$ butterfly needle; Greiner Bio-One $\mathrm{GmbH}$, Austria), containing EDTA for anticoagulation.

Blood of the antelopes was cooled in insulated bags during the transport from the NZG to the University of Pretoria Biomedical Research Center (UPBRC), and analyzed within 6 hours following withdrawal. Blood of sheep and cows was tested immediately after blood withdrawal. RBC deformation was tested by rotational laser ektacytometry at $37^{\circ} \mathrm{C}$ (Rheodyn SSD, Myrenne, Germany), and RBC aggregation was tested by light transmission (MA1; Myrenne, Germany) at ambient temperature, which was approximately $22^{\circ} \mathrm{C}$, set by air condition in the lab. In laser diffractometry, the RBC volume should be normalized before elongation indices (EI) can be compared between study groups. The shear stress (SS) that is needed for the half-maximal deformation of a $\mathrm{RBC}\left(\mathrm{SS}_{1 / 2}\right)$ out of the EI/SS dependency was therefore calculated according to Baskurt et al. [37]. Maximum elongation index $\left(\mathrm{EI}_{\max }\right)$, was extrapolated from the EI/SS dependency. Whole blood was centrifuged 5 minutes at $2000 \mathrm{~g}$, and plasma viscosity was measured by the AMVn rolling ball viscometer at $37^{\circ} \mathrm{C}$ (Anton Paar, Austria). Packed cell volume (PCV) was measured by centrifugation (Hettich, Germany), and 
Table 1

RBC deformability, RBC aggregability, and plasma viscosity in four scimitar oryx antelopes and 10 dromedary camels. Since camelid RBCs cannot be measured by laser diffractometry, Nguni cows and Merino sheep are included to show the relevance of the oryx data. Data represent median values and quartiles in parentheses. Asterisks indicate own laboratory reference values

\begin{tabular}{lccccccc}
\hline & $\mathrm{SS}^{1} / 2(\mathrm{~Pa})$ & $\mathrm{EI}_{\max }$ & $\mathrm{M} 0$ & $\mathrm{M} 1$ & $\mathrm{PV}(\mathrm{mPa} . \mathrm{s})$ & $\mathrm{B}_{10 \mathrm{~s}-1}$ & $\mathrm{~B}_{1000 \mathrm{~s}-1}$ \\
\hline $\begin{array}{l}\text { Oryx dammah } \\
\text { Camelus drome- }\end{array}$ & $3.67(2.52 / 4.95)$ & $22.6(19.2 / 25.3)$ & $5.2(3.3 / 6.7)$ & $18.1(16.7 / 27.9)$ & $1.22(1.16 / 1.34)$ & $\mathrm{N} / \mathrm{A}$ & $\mathrm{N} / \mathrm{A}$ \\
$\quad-$ & - & $0(0 / 0)$ & $0.55(0.03 / 1.73)$ & $1.06(1.05 / 1.07)$ & -0.07 & -0.06 \\
$\quad$ Narius & & & & & & & \\
Muni cattle & $5.91(5.85 / 5.96)$ & $28.7(28.6 / 28.8)$ & $0.7(0.3 / 1.2)$ & $4.4(3.7 / 7.7)$ & N/A & N/A & N/A \\
Human sheep & $0.86(0.69 / 1.36)$ & $5.6(5.4 / 6.9)$ & $0(0 / 0)$ & $7.8(6.7 / 8.15)$ & N/A & N/A & N/A \\
& - & - & $5.8 \pm 0.5^{*}$ & $28.5 \pm 6.6 *$ & $1.29(1.25 / 1.36) *$ & -0.27 & -0.21 \\
\hline
\end{tabular}

plasma total protein concentration was determined by refractometry (Krüss, Germany). Data are shown in Table 1.

Blood of the camels was immediately analyzed following withdrawal in the laboratory of the CRC by the Physica MCR302 rheometer (Anton Paar, Austria) for blood and plasma viscosity. Tests were finalized within 6 hours following withdrawal. Plasma was separated from whole blood through centrifugation at $2000 \mathrm{~g}$ for 5 minutes and tested at the same temperature intervals like whole blood. Packed cell volume (PCV) was assessed by centrifugation, and total protein was tested by refractometry as described above. A stainless steel double gap cylinder system (internal gap: $0.417 \mathrm{~mm}$; external gap: $0.462 \mathrm{~mm}$, cup length: $42 \mathrm{~mm}$ ) was used to test apparent shear viscosity of the native blood samples. The temperature in the system was Peltier controlled. Several flow curves were performed starting with the highest applied strain $\left(1000 \mathrm{~s}^{-1}\right)$ to the lowest one $\left(10 \mathrm{~s}^{-1}\right)$, set at a logarithmic shear rate ramp with 16 data points per measurement. The first flow curve was performed at $42^{\circ} \mathrm{C}$, followed by subsequent tests in $5^{\circ} \mathrm{C}$ temperature decrements, during which the sample remained in the measuring system until the lowest temperature was reached $\left(12^{\circ} \mathrm{C}\right)$. A constant $30 \mathrm{~s}$ pre-shear at $300 \mathrm{~s}^{-1}$ after each temperature equilibration to the next decrement was included to the protocol to quench all pre-existing shear history prior to each flow curve. There was no syneresis observed with our camel blood samples, which allowed us to test the samples subsequently at the different temperature steps. However at shear rates below $10 \mathrm{~s}^{-1}$ the error bars became high probably due to the proximity to the instrument detection limit due to the low viscosity of blood. In subsequent tests we therefore set the shear rate rage to a smaller interval from 1000 to $10 \mathrm{~s}^{-1}$ only. RBC aggregation of native samples was tested by MA1 (Myrenne, Germany) at ambient temperature.

Neither in the camels, nor in the oryx we were able to perform a hemogram of the animals tested. Concerning the camels, we refer to the database held from this herd of animals at the CRC.

Descriptive statistic was performed by IBM $^{\circledR}$ SPSS (24.0). To show the influence of temperature (T) on whole blood viscosity (WBV), the WBV (in $\mathrm{mPa}^{*} \mathrm{~s}$ )/T (in ${ }^{\circ} \mathrm{C}$ ) relationship at $1000 \mathrm{~s}^{-1}$ and $10 \mathrm{~s}^{-1}$ was tested according to the formula: $\mathrm{WBV}=\mathrm{B} * \mathrm{~T}+\mathrm{h}$.

\section{Results}

Packed cell volume (PCV) was 33.5\% (26.25/37.75) in the oryx and 27\% (25/29) in the camel, thus relatively low in both species compared to other mammalian species and man. Total protein concentration was $60.5 \mathrm{~g}^{*} \mathrm{~L}^{-1}(57.3 / 65.3)$ in the oryx, and $63 \mathrm{~g} * \mathrm{~L}^{-1}(58 / 66)$ in the camel. A hemogram of the camels' and antelope's blood to provide MCV and MCHC could not be performed. 
According to the literature, the MCV of horned oryx is about $40 \mathrm{fL}[38,39]$. According to the database of the CRC, MCV in the camels of the herd is $30 \mathrm{fL}(28 / 31)$, and $\mathrm{MCHC}$ is $47.7 \mathrm{~g}^{*} \mathrm{dL}^{-1}(46.3 / 48.2)$, which is close to reference values [40].

Data in Table 1 shows the deformability of oryx RBCs between the values obtained for Merino sheep and Nguni cows. RBC aggregability was increased compared to the other species (sheep, cow, camel). The influence of temperature on camel blood viscosity was decreased compared to human blood. At $10 \mathrm{~s}^{-1}$, blood viscosity in camel increased from $2.18 \mathrm{mPa}^{*} \mathrm{~s}(2.01 / 2.37)$ at $42^{\circ} \mathrm{C}$ to only $4.39 \mathrm{mPa}^{*} \mathrm{~s}(4.22 / 4.51)$ at $12^{\circ} \mathrm{C}$. In human blood, viscosity ranged from $8.21 \mathrm{mPa} *^{\mathrm{s}}(6.95 / 8.25)$ at $37^{\circ} \mathrm{C}$ to $15.52 \mathrm{mPa}^{*} \mathrm{~s}(14.25 / 16.03)$ at $12^{\circ} \mathrm{C}$. At $1000 \mathrm{~s}^{-1}$, blood viscosity in camel ranged from $2.00 \mathrm{mPa}^{*} \mathrm{~s}(1.95 / 2.04)$ at $42^{\circ} \mathrm{C}$ to $3.98 \mathrm{mPa}^{*} \mathrm{~s}(3.88 / 4.08)$ at $12^{\circ} \mathrm{C}$. For human blood, viscosity ranged from $5.35 \mathrm{mPa}^{*} \mathrm{~s}(4.96 / 5.87)$ at $37^{\circ} \mathrm{C}$ to $11.24 \mathrm{mPa}^{*} \mathrm{~s}(10.06 / 11.17)$ at $12^{\circ} \mathrm{C}$.

Figure 1 shows the EI/SS dependency at shear stresses between 0.3 and $60 \mathrm{~Pa}$ of the oryx, Nguni cows, and Merino sheep blood samples on a linear scale to better express the differences in maximum elongation of the RBCs. SS $1 / 2$ and $\mathrm{EI}_{\max }$ values are provided in Table 1 together with the aggregation indices, the plasma viscosity and the regression coefficients for the temperature dependency. For comparison, human reference data [14] and own laboratory reference values are included. For these reference values, blood was collected at the Medical University Vienna from 10 human volunteers after informed consent (ethics approval: 1892/2013). Coefficient B in Table 1, indexed by the shear rate at which the linear regression was calculated, represents the effect of the independent variable "temperature" on the dependent variable "WBV". Figure 2 illustrates the decrease of $\mathrm{WBV}_{10 \mathrm{~s}-1}$ with the increase of temperature in dromedary camel and human blood at equivalent PCV levels.

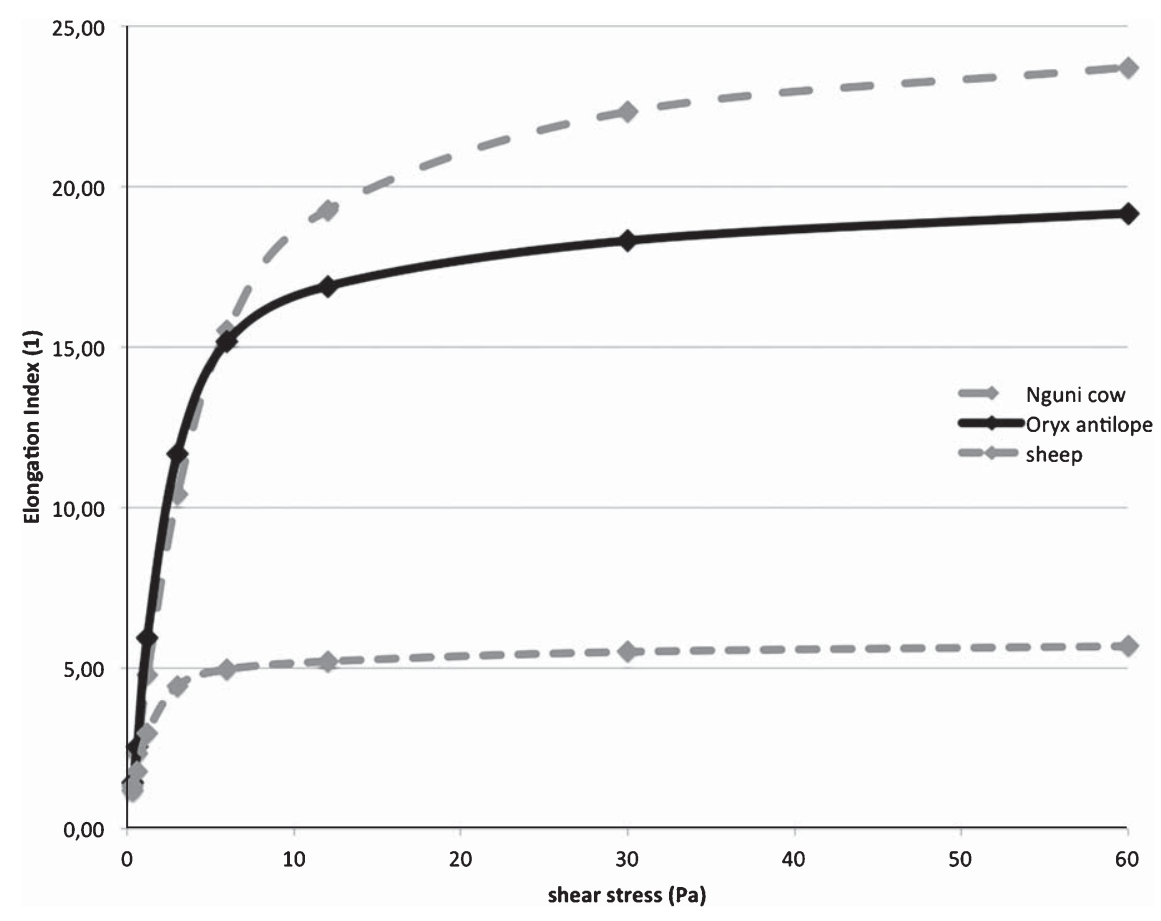

Fig. 1. EI/SS dependency of RBCs scimitar-horned oryx antelopes in Couette flow, in comparison to Nguni cows and Merino sheep. 


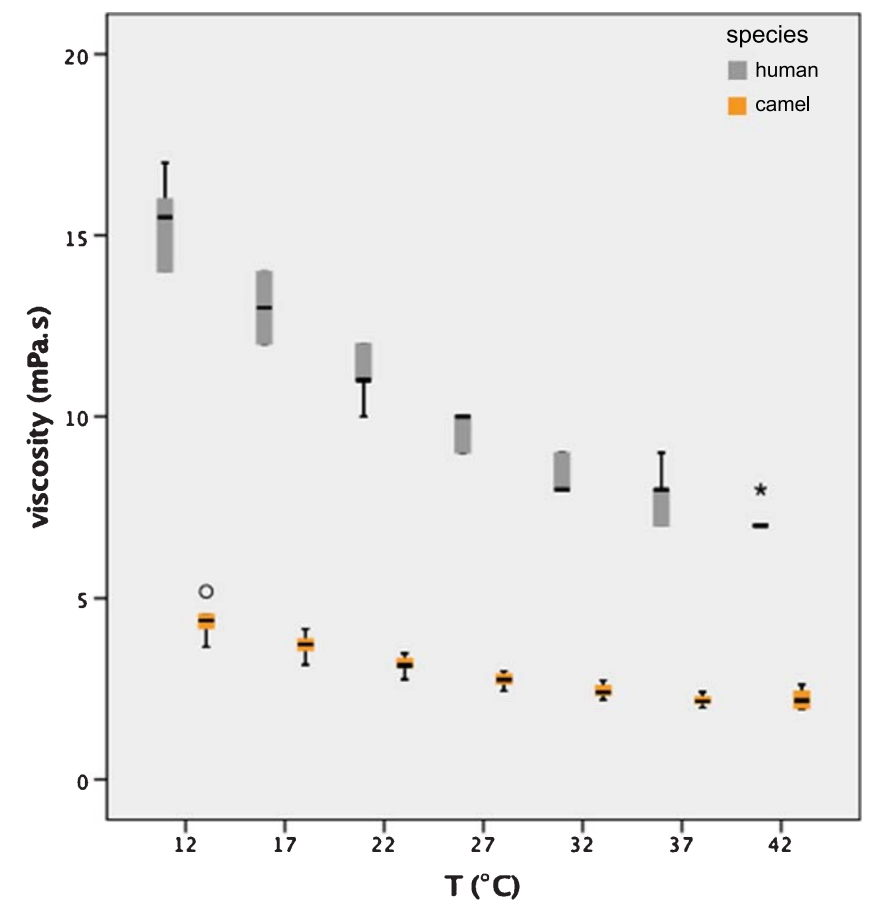

Fig. 2. Apparent viscosity of native whole blood at $10 \mathrm{~s}^{-1}$ of dromedary camels $(27 \%(25 / 29) ; n=10)$ compared to human whole blood at $30 \% \operatorname{HCT~}\left(n=10\right.$; blood was tested at $42^{\circ} \mathrm{C}$ in two individuals only). Blood viscosity is reduced in dromedary camel, and the effect of temperature on viscosity is diminished as well.

\section{Discussion}

Scimitar oryx antelope's red blood cells show significant aggregability and deformability in contrast to Merino sheep and Nguni cows, whereas RBC aggregation in dromedary camel blood was only minute. Temperature had less of an effect on dromedary camel blood viscosity compared to human blood.

\subsection{RBC Aggregation}

In contrast to our group of oryx antelopes, the endemic Nguni cattle and the South African Merino sheep that were also tested in this study did not show a relevant RBC aggregation (see Table 1). Generally, domestic goat, sheep, and cattle are known as species with low RBC aggregability, and the South African sheep and cows confirm this. We may assume that environment does not influence RBC aggregability of a species, since the aggregation indices were essentially equal in domestic ruminants in South Africa and in central Europe. For instance, there is no difference between the South African Merino sheep of this study and the Milchschaf and Bergschaf race in Austria [data from 41]. There is also no relevant difference between the Nguni cattle, and the Simmental breed, raised in Austria [42]. The reason for the presence or absence of RBC aggregation in several species is still a matter of discussion [15].

In a study on a wide range of animal species including several zoo animals [38] it was shown that blood viscosity at $0.277 \mathrm{~s}^{-1}$ was higher in musk ox and bison compared to domestic cattle and yak. All these species belong to the same zoological family. A possible explanation is that RBC aggregability in musk ox and bison may be higher than in the domesticated animals that we generally use for 
livestock. This is in line with our observation of low aggregation indices in Nguni cattle, which is dual purpose bred (milk and meat) by the farmers in Gauteng. Regarding the family of the antilopinae that more reflect the oryx, blood viscosity of black buck (Antilope cervicapra) and pronghorn antelope (Antilocapra Americana) was much higher than the values of the domestic sheep tested in these studies $[38,43]$. And RBC aggregation indices of our oryx antelopes were also higher than the indices of our sheep. Other ruminants that belong to the tragelaphini genus or the cervidae family in the study of Johnn et al. [38] also showed higher blood viscosity at low shear, and higher shear thinning than the domestic ruminants (sheep, cow) of the same study. Deers and antelopes probably are athletic species and indeed, by linear regression of maximum oxygen consumption of pronghorn antelope, horse, and dog versus their logarithmic low shear blood viscosity values (at $0.277 \mathrm{~s}^{-1}$ ), Popel et al. [43] found that the aerobic capacity of a species correlated with its blood viscosity value. Unfortunately, the authors did not measure RBC aggregation indices. But erythrocyte sedimentation rate, which can be used to estimate RBC aggregation, was also higher in horse, antelope and dog compared to cow and sheep. The authors came to the conclusion that athletic species show RBC aggregability, whereas the sedentary species do not. The presence of RBC aggregation is associated with an important physiological effect. Briefly, the ability of blood for shear thinning is expected to lower the capillary pressure by balancing pre- versus the post-capillary resistance, and as such prevent edema formation during exercise. The mechanism is described in detail in a recent textbook [15]. From this point of view, domestic cattle, sheep and goats as well as camels would belong to the sedentary animal group, and movement of animals during pasture management should be undertaken with care. Camels do not show RBC aggregation (the aggregation index M1 in Table 1 rather indicates a kind of packing during rotating flow), but they are used for racing purposes in many countries, especially in the Middle East. They do not show clinical signs of intramuscular edema that would require medical treatment. Possibly, the relationship between RBC aggregation and the athletic phenotype seem to be not applicable to the camel. It was proposed recently [15] that RBC aggregation requires a biconcave cell shape and our results contribute to this assumption. Although the aggregometer displays an aggregation index at M1 mode, it may rather represent a kind of packing of the elliptic camel RBCs while the cone rotates. Even when camel blood is slowly turned upside down and back again within a vacutainer tube, it creates the impression of a somehow "granular" fluid (personal observation). Avian blood generates the same impression. Freshly withdrawn camel blood also appears to be of a brighter red than blood from rats or horses [44]. Clearly, the camel blood suspension should be more thoroughly investigated. Concerning the lack of RBC aggregation, there must be other mechanisms in the dromedary camel to keep the capillary filtration pressure low during activity. On the other hand, by taking into account the argument of Popel et al. [43], the presence of RBC aggregation in the oryx antelope can be a clear benefit for a free ranging animal exposed to predators by providing a blood-based mechanism to maintain the capillary pressure.

\subsection{RBC Deformation}

Concerning RBC deformability, the biconcave oryx red cells showed $\mathrm{SS}^{1 / 2} 2$ and $\mathrm{EI}_{\text {max }}$ values between those of South African Merino sheep and Nguni cattle. The elliptic camelid RBCs cannot be probed for their elongation in Couette flow, similar to the nucleated RBCs of non-mammalian vertebrates [45]. Sheep is commonly classified as a species with low RBC deformability [46] if maximum red cell elongation is used to rank the species. However, $\mathrm{EI}_{\max }$ is influenced by red cell size, and this may be also the reason for the higher $\mathrm{EI}_{\max }$ value in the Nguni cows. The shear stress that is needed for half-maximal deformation ( $\mathrm{SS}^{1 / 2}$ ) can be used to exclude the size factor [37]. By this approach, RBCs of our South African Merino sheep showed better initial deformation than several other species, which we have tested with the Rheodyn SSD device [47]. Tests with another laser diffractometer confirm this 
finding [45]. This demonstrates that the deformability of ovine RBCs is not that poor as expected from the low $\mathrm{EI}_{\max }$ value alone. To rank oryx RBC deformability, a larger number of species must be used. Out of a series of seven species [47] the $\mathrm{EI}_{\max }$ value of oryx ranges together with horse in a group with rather reduced deformability, and oryx red cell volume is only little lower than horse MCV [38, 48, 49]. However, $\mathrm{SS}^{1} / 2$ is much lower than in horse, which shows that oryx RBCs need lower stress for initial red cell elongation than horse RBCs. Therefore oryx RBCs show better deformability than horse RBCs. In summary, oryx RBCs deformability seems to be y intermediate among this series of seven species. RBC deformability is provided by the elasticity of the RBC membrane cytoskeleton and the connectivity of the spectrin network to the bilayer by the membrane proteins. In addition, the cytoplasm is connected to the cytoskeleton by the interaction of desoxyhemoglobin with the cytoplasmic domain of band 3 proteins [50]. This increases the hydrodynamic influence of the cytoplasm on the bilayer. $\mathrm{MCHC}$ can be used to estimate the cytoplasmic viscosity, and from that point it would result that a high MCHC reduces RBC deformation. MCHC in Arabian oryx antelopes is between 31 and $33 \mathrm{~g}^{*} \mathrm{dL}^{-1}$, and thus in a "normal" range or even less compared to many other species [39, 48, 49]. If scimitar oryx RBCs have comparable MCHC, the cytoplasmic viscosity is definitely not the reason for the observed intermediate red cell deformability. Membrane "strengthening" might occur in the oryx due to the high ankyrin content [20]. This would favor the integrity of RBCs during water deprivation in summer.

\subsection{Specific feature of the dromedary camel}

A species, which is perfectly adapted to abrupt changes in plasma osmolality, is the dromedary camel. This even allows a quick water shift from the alimentary tract to the circulating blood after drinking [51] in contrast to other desert ungulates. Camelid RBCs are elliptic and have a constant thickness of $1.0-1.1 \mu \mathrm{m}$; their surface-to-volume ratio is only one third of human red cells $[52,53]$. The MCHC is very high $\left(46-51 \mathrm{~g}^{*} \mathrm{dL}^{-1}\right)$, which results in a high cytoplasmic viscosity, since viscosity scales up in a non-linear fashion with MCHC [54]. In the camel, the marginal band on the cell poles and the high content of integral proteins in the red cell bilayer together with the close connection of band 3 protein to ankyrin fortify the RBCs against mechanical stress $[7,24,25]$. Such a "strengthening" of cell membranes could be a typical requisite for desert animals. This hypothesis is supported by a recent study using proteomics [7]. If species are adapted to periodic dehydration-rehydration cycles and fluid shifts between body compartments, there should be mechanisms that prevent cells from mechanical destruction due to the accompanying changes of the ionic environment. Camel RBCs feature such structures, since they can remain intact even during massive swelling [55]. Such high water uptake during rehydration is made possible by a high diffusional permeability of the membrane for the water molecule, by the microtubular system (the marginal band) to augment intracellular transport processes, and by a high hydrophilicity of the hemoglobin molecule $[56,57]$. The prize to pay for any contribution to membrane stabilization is the resulting reduction in RBC deformability. Finally, it is unclear if it is aimed at simply withstanding the fluctuations in osmolality, or if such stabilizing objects should even conserve intracellular water for a later use.

Camels experience heterothermy especially in periods of water deprivation [6]. When oryx antelopes have restricted access to water or when they live in arid regions with scarce water resources they also experience heterothermy. Antelopes with ad libitum access to water remained homeotherm, even at an ambient temperature of $50^{\circ} \mathrm{C}[8,32]$. Heterothermy was also observed in several other gazelles [for summary see 58]. The lowest body temperature is found in the morning when the cooler peripheral blood is mixed with the warmer core blood. When the camel is exposed to rhythmical changes in blood temperature, concomitant changes of blood viscosity will occur. Since blood viscosity influences the flow resistance [59, 60] and the frictional resistance at the vessel wall [61], this would mean that these circumstances undergo diurnal changes. By testing the temperature dependency of the apparent 
viscosity of dromedary camel native blood in-vitro, it emerged [1] that blood viscosity was lower in the camel compared to human at each temperature, and [2] that camel blood viscosity was rather constant during the temperature change unlike human blood at equal hematocrit. Therefore, fluctuations in blood viscosity during heterothermy will be low, reducing the need of the endothelium to transduce periodically changing shear stresses. This could reflect a mechanism to conserve energy [4] and would reduce heat production. The low temperature dependency of blood viscosity was observed at low and at high shear rate, indicating that each part of the vascular system experiences the same effect.

\section{Acknowledgments}

The authors are grateful to Prof. Antoinette Kotze from the National Zoological Gardens, Pretoria, and the experienced team of the Camel Reproduction Center for supporting us with blood samples from the antelopes and camels. We are also indebted to Ms. Dina Baier MSc, for performing AFM experiments on camel RBCs.

The data was presented in part at the 1st Hemorheology Days 2017 in Puchberg am Schneeberg, Austria.

\section{References}

[1] Gaughan JB. Which physiological adaptation allows camels to tolerate high heat load - and what more can we learn? J Camelid Sci. 2011;4:85-8.

[2] Cain III JW, Krausman PR, Rosenstock SS, Turner JC. Mechanisms of thermoregulation and water balance of desert ungulates. Wildlife Society Bulletin. 2006;34:570-81.

[3] Yousef MK, Dill DB, Mayes MG. Shifts in body fluids during dehydration in the burro, Equus asinus. J Appl Physiol. 1970;29:345-9.

[4] Schmidt-Nielsen K, Crawford EC, Newsome AE, Rawson KS, Hammel HT. Metabolic rate of camels: Effect of body temperature and dehydration. Am J Physiol. 1967;212:341-6.

[5] Elkhawad AO. Selective brain cooling in desert animals: The camel (Camelus dromedarius). Comp Biochem Physiol. 1992;101A:195-201.

[6] Bouaouda H, Achaaban MR, Ouassat M, Oukassou M, Piro M, Challet E, El Allali K, Pevet P. Daily regulation of body temperature rhythm in the camel (Camelus dromedarius) exposed to experimental desert conditions. Physiol Reports. 2014;2:e12151.

[7] Warda M, Prince A, Kim HK, Khafaga N, Scholkamy T, Linhardt RJ, Jin H. Proteomics of old world camelid (Camelus dromedarius): Better understanding the interplay between homeostasis and desert environment. J Adv Res. 2014;5: 219-42.

[8] Hetem RS, Strauss WA, Fick LG, Maloney SK, Meyer LCR, Shobrak M, Fuller A, Mitchell D. Variation in the daily rhythm of body temperature of free-living Arabian oryx (Oryx leucoryx): Does water limitation drive heterothermy? J Comp Pathol. 2010;180:1111-9.

[9] Maloney SH, Fuller A, Mitchell G, Mitchell D. Brain and arterial blood temperatures of free-ranging oryx (Oryx gazelle). Pflugers Arch. 2002;443:437-45.

[10] Mitchell D, Maloney SK, Jessen C, Laburn HP, Kamerman PR, Mitchell G, Fuller A. Adaptive heterothermy and selective brain cooling in arid-zone mammals. Comp Biochem Physiol. 2002;131B:571-85.

[11] Martini J, Carpentier B, Chavez Negrete A, Cabrales P, Tsai AG, Intaglietta M. Beneficial effects due to increased blood and plasma viscosity. Clin Hemorheol Microcirc. 2006;35:51-7.

[12] Bertuglia S. Increased viscosity is protective for arteriolar endothelium and microvascular perfusion during severe hemodilution in hamster cheek pouch. Microvasc Res. 2000;61:56-63.

[13] Dietrich HH, Ellsworth ML, Sprague RS. Red blood cell regulation of microvascular tone through adenosine triphosphate. Am J Physiol. 2000;278:H1294-8.

[14] Pöschl CH. Die Vollblutviskosität in Abhängigkeit von Hämatokrit und Temperatur. Thesis Medical University Vienna, 2015.

[15] Baskurt OK, Neu B, Meiselman HJ. Red blood cell aggregation. CRC press, Boca Raton, FL, 2012. 
[16] Chebbi R. Dynamics of blood flow: Modeling of the Fahraeus-Lindqvist effect. J Biol Phys. 2015;41:313-26.

[17] Stoiber B, Zach C, Izay B, Windberger U. Whole blood, plasma viscosity, and erythrovyte aggregation as a determining factor of competitiveness in standard bred trotters. Clin Hemorheol Microcirc. 2005;32:31-41.

[18] Auer R, Gleiss A, Windberger U. Towards a basic understanding of the properties of camel blood in response to exercise. Emir J Food Agric. 2015;27:302-11.

[19] Luo ZY, Bai BF. Dynamics of biconcave vesicles in a confined shear flow. Chem Engineering Sci. 2005; 137:548-55.

[20] Omorphos SA, Hawkey CM, Rice-Evans C. The elliptocyte: A study of the relationship between cell shape and membrane structure using the camelid erythrocyte as a model. Comp Biochem Physiol. 1989;94B:789-95.

[21] Warda M, Zeisig R. Phospholipid- and fatty acid-composition in the erythrocyte membrane of the one-humped camel and its influence on vesicle properties prepared from these lipids. Dtsch Tieraerztl Wschr. 2000;107:349-88.

[22] Al-Quarawi AA, Mousa HM. Lipid concentrations in erythrocyte membranes in normal, starved, dehydrated and rehydrated camels (Camelus dromedarius), and in normal sheep (Ovis aries) and goats (Capra hircus). J Arid Environ. 2004;59:675-83.

[23] Eitan A, Aloni B, Livne A. Unique properties of the camel erythrocyte membrane II. Organisation of membrane proteins. Biochim Biophys Acta. 1976:426:647-58.

[24] McPherson RA, Sawyer WH, Tilley L. Band 3 mobility in camelid elliptocytes: Implications for erythrocyte shape, Biochemistry. 1993;32:6696-702.

[25] Ralston GB. Protein components of the camel erythrocyte membrane. Biochim Biophys Acta. 1975;401:83-94.

[26] Waugh RE. Red cell deformability in different vertebrate animals. Clin Hemorheol. 1992;12:649-56.

[27] Khodadad JK, Weinstein RS. The band 3-rich membrane of Ilama erythrocytes: Studies on cell shape and the organisation of membrane proteins. J Membrane Biol. 1983;72:161-71.

[28] Waugh RE, Evans EA. Thermoelasticity of red blood cell membrane. Biophys J. 1979;26:115-32.

[29] Hochmuth R. Properties of red blood cells. In: Skalak R \& Chien S, editors. Handbook of Bioengineering New York: McGraw-Hill Book Comp; 1987. Chapt. 12.

[30] Elsner R, Meiselman HJ, Baskurt OK. Temperature-viscosity relations of bowhead whale blood: A possible mechanism for maintaining cold blood flow. Marine Mammal Science. 2004;20:339-44.

[31] Guard CL, Murrish DE. Effects of temperature on the viscous behavior of blood from antarctic birds and mammals. Comp Biochem Physiol. 1975;52A:287-90.

[32] Fuller A, Moss DG, Skinner JD, Jessen PT, Mitchell G, Mitchell D. Brain, abdominal, and arterial temperatures of free-ranging eland in their natural habitat. Pflugers Arch. 1999;438:671-80.

[33] Preziosi V, Tomaiuolo G, Fenizia M, Caserta S, Guido S. Confined tube flow of low viscosity emulsions: Effect of matrix elasticity. J Rheology. 2016;60:419-32.

[34] Ouajd S, Kamel B. Physiological particularities of dromedary (Camelus dromedarius) and experimental implications. 2009;36:19-29.

[35] Tran-Son-Tay R, Sutera SP, Rao PR. Determination of red blood cell membrane viscosity from rheoscopic observations of tank-threading motion. Biophys J. 1984;46:65-72.

[36] Nash GB, Meiselman HJ. Red cell and ghost viscoelasticity. Biophys J. 1983;43:63-73.

[37] Baskurt OK, Meiselman HJ. Analyzing shear stress-elongation index curves: Comparison of two approaches to simplify data presentation. Clin Hemorheol Microcirc. 2004;31:23-30.

[38] Johnn H, Phipps C, Gascoyne S, Hawkey C, Rampling MW. A comparison of the viscometric properties of the blood from a wide range of mammals. Clin Hemorheol Microcirc. 1992;12:639-47.

[39] Hawkey CM, Hart MG. Age-related changes in the blood count of the scimitar-horned oryx (Oryx tao). J Zoo Anim Med. 1984; 15:157-60.

[40] Saaed A, Hussein MM. Change in normal haematological values of camels (Camelus dromedaries): Influence of age and sex. Comp Clin Pathol. 2008;17:263-6.

[41] Windberger U, Bartholovitsch A, Plasenzotti R, Korak KJ, Heinze G. Whole blood viscosity, plasma viscosity and erythrocyte aggregation in nine mammalian species: Reference values and comparison of data. Exp Physiol. 2003;88.3:431-40.

[42] Schmeidl K. Hämorheologische Eigenschaften des afrikanischen Nguni-Rindes und der Vergleich zum österreichischen Fleckvieh. Thesis, Veterinary University Vienna, Austria, 2010.

[43] Popel AS, Johnson PC, Kameneva MV, Wild MA. Capacity for red blood cell aggregation is higher in athletic mammalian species than in sedentary species. J Appl Physiol. 1994;77:1790-4.

[44] Grint N, Dugdale A. Brightness of venous blood in South American camelids: Implications for jugular catheterization. Vet Anaesth Analg. 2009;36:63-6.

[45] Windberger U, Baskurt OK. Comparative hemorheology. In: Baskurt OK, Hardeman MR, Meiselman HJ editors. Handbook of Hemorheology and Hemodynamics, Amsterdam: IOS press; 2007. 
[46] Plasenzotti R, Stoiber B, Posch M, Windberger U. Red blood cell deformability and aggregation behaviour in different animal species. Clin Hemorheol Microcirc. 2004;31:105-11.

[47] Windberger U. Animal blood suspensions. In: Suspension dynamics of blood cells in microflow. Abkarian M, Viallat A. editors. Boca Raton: CRC press; chapter 10. 2018, submitted.

[48] Vassart M, Greth A. Hematological and serum chemistry values for Arabian oryx (Oryx leucoryx). J Wildlife Diseases. 1991;27:506-8.

[49] Hussein MF, Al-jumaah RS, Homeida A, Alhaidary AA, Alshaikh MA, Garelnabi A, Mohamed O, Omer S. Hemostatic profile, platelets, and blood constituents of the Arabian oryx (Oryx leucoryx). Comp Clin Pathol. 2010;19:585-91.

[50] Weber RE, Voelter W, Fago A, Echner H, Campanella E, Low PS. Modulation of red cell glycolysis: Interaction between vertebrate hemoglobins and cytoplasmic domains of band 3 red cell membrane proteins. Am J Physiol. 2004;287:R45464.

[51] Schmidt-Nielsen K. Desert animals: Physiological problems of heat and water. New York: Dover press; 1979.

[52] Yamaguchi K, Jurgens KD, Bartels H, Piiper J. Oxygen transfer properties and dimensions of red blood cells in high-altitude camelids, dromedary camel and goat. J Comp Physiol. 1987;157:1-9.

[53] Vap L, Bohn AA. Hematology of camelids. Vet Clin Exot Anim. 2015;18:41-9.

[54] Ross, PD, Minton AP. Hard quasispherical model for the viscosity of hemoglobin solutions. Biochem Biophys Res Comm. 1977;76:971-6.

[55] Yagil R, Sod-Moriah, Meyerstein N. Dehydration and camel blood. II. Shape, size, and concentration of red blood cells. Am J Physiol. 1974;226:301-4.

[56] Benga Gh, Grieve SM, Chapman BE, Gallagher CH, Kuchel PW. Comparative NMR studies of diffusional water permeability of red blood cells from different species. X. Camel (Camelus dromedarius) and Alpaca (Lama pacos). Comp Clin Pathol. 1999;9:43-8.

[57] Abdo MS, Ali AM, Prentis PF. Fine structure of camel erythrocytes in relation to its functions. Zschr Mikr Anat Forsch. 1990;104:440-8.

[58] Wilson RT. Ecophysiology of the camelidae and desert ruminants. Berlin, Heidelberg: Springer; 1989.

[59] Cabel M, Meiselman HJ, Popel AS, Johnson PC. Contribution of red blood cell aggregation to venous vascular resistance in skeletal muscle. Am J Physiol. 1997;272:H1020-32.

[60] Yalcin O, Uyuklu M, Armstrong JK, Meiselman HJ, Baskurt OK. Graded alterations of RBC aggregation influence in vivo blood flow resistance. Am J Physiol. 2004;287:H2644-50.

[61] Baskurt OK, Meiselman HJ. Blood rheology and hemodynamics. Semin Thromb Hemostas. 2003;29:435-50. 